\title{
EXTREME LATERAL INTERBODY FUSION IN PACIENTS WITH CHRONIC LOW BACK PAIN
}

\section{FUSÃO INTERSOMÁTICA POR VIA EXTREMO LATERAL EM PACIENTES COM LOMBALGIA CRÔNICA}

\author{
alberto augusto Neto ${ }^{1}$ (i), Rennan Guilherme Dias $^{1}$ (i), Marcelo Wajchenberg ${ }^{2,3}$ (i), Delio Martins ${ }^{1,2}$ (i) \\ 1. Universidade Anhembi Morumbi, São Paulo, SP, Brazil. \\ 2. Hospital Israelita Albert Einstein, São Paulo, SP, Brazil. \\ 3. Universidade Federal de São Paulo, Paulista School of Medicine, Department of Orthopedics and Traumatology, São Paulo, SP, Brazil.
}

\section{ABSTRACT}

Objective: To evaluate the effect of lateral lumbar interbody fusion (LLIF) or oblique interbody fusion (OLIF) on low back pain due to degenerative intervertebral disc disease. Methods: We systematically reviewed articles on surgical treatment of low back pain by LLIF and OLIF, according to the Cochrane Handbook for Systematic Reviews of Interventions. We searched through electronic databases, including Medline via PubMed, Lilacs through the Virtual Health Library (VHL), Cochrane Collaboration/Central and Cohrane/Dare Cochrane Controlled Trials Register, without language or publication date restrictions and with design for prospective cohorts and randomized clinical trials. Results: We have selected and presented three studies. Conclusion: The literature review showed great relevance in the improvement of the new surgical approach (LLIF) in relation to TLIF, but greater content availability in the databases is necessary to reach a satisfactory conclusion regarding the efficiency of the lateral approach and its advantages over other traditional procedures. Level of Evidence II, Systematic review of Level II studies.

\section{RESUMO}

Objetivo: Avaliar o efeito da técnica de fusão intersomática lateral lombar (LLIF) ou da fusão intersomática obliqua (OLIF) na lombalgia em decorrência de doença degenerativa do disco intervertebral. Método: Revisamos estudos de abordagem cirúrgica LLIF e OLIF, de acordo com o Manual Cochrane para Revisões Sistemáticas de Intervenções. A busca foi realizada, por meio de bases de dados eletrônicos, incluindo Medline via PubMed, Lilacs via Biblioteca Virtual em Saúde (BVS), Registro de ensaios Controlados da Colaboração Cochrane/Central e Cohrane/Dare, sem restrições de idiomas ou de data de publicações e com delineamento para coortes prospectivos e ensaios clínicos randomizados. Resultados: Selecionamos e apresentamos três estudos. Conclusão: Houve relevância na melhora da nova abordagem cirúrgica (LLIF) em relação à abordagem tradicional, porém é necessário maior disponibilidade de conteúdo nas bases de dados para que seja obtida conclusão quanto à eficiência da via lateral e seus benefícios em relação às demais abordagens tradicionais. Nível de Evidência II, Revisão sistemática de Estudos de Nível II.

Keywords: Low Back Pain. Intervertebral Disc. Arthrodesis

Descritores: Dor lombar. Disco Intervertebral. Artrodese

Citation: Neto AA, Dias RG, Wajchenberg M, Martins D. Extreme lateral interbody fusion in patients with chronic low back pain. Acta Ortop Bras. [online]. 2020;28(5):256-260. Available from URL: http://www.scielo.br/aob.

\section{INTRODUCTION}

Low back pain is a symptom that may be caused by ligament, muscle, nerve and intervertebral disc (ID) changes, besides arising from psychosocial, occupational, obesity and age conditions, with a prevalence of $85 \%$ in the population. ${ }^{1,2}$ Low back pain shows important correlation with degenerative disc disease (DDD), which consists of a chronic and natural aging process, progressing steadily through the decline in the concentration of proteoglycans in the $\mathrm{DI}$, decreased hydration and loss of gelatinous consistency of the nucleus pulposus, generating changes in the functional properties of the disc, with this process being most commonly found in the lower lumbar regions (L4/L5 and L5/S1). ${ }^{3,4}$
With the evolution of degeneration, other secondary diseases such as herniated disc, intervertebral foramen stenosis (EFI), deformities such as scoliosis, and spondylolisthesis may be associated. ${ }^{1,5}$ Radicular symptoms and intermittent claudication in the lower extremities are generally linked to EFI and thus a factor for decreased quality of life, especially in older adults. Due to the difficulty of treatment with conservative management, new surgical methods and approaches were introduced, such as interbody fusion. ${ }^{6}$ The pioneering technique is posterior lumbar interbody fusion (PLIF), which mimics the natural repair of degenerative disc disease. This technique led to the introduction of the concept of independent interbody fusion devices. ${ }^{6,7}$

All authors declare no potential conflict of interest related to this article. 
From this, other techniques emerged such as transforaminal lumbar interbody fusion (TLIF) and anterior lumbar interbody fusion (ALIF), but these techniques together with PLIF were associated with some post-surgical complications such as: retrograde ejaculation, sympathetic chain injury, vascular complications, colonic obstruction, dural tear, radiculitis, and denervation of the paravertebral musculature. ${ }^{6}$ As an alternative to avoid these complications, minimally invasive techniques were developed, with extreme lateral interbody fusion (LLIF) and oblique interbody fusion (OLIF) being implemented. ${ }^{6,8,9}$ This study aims to evaluate and establish the possible benefits of minimally invasive methods of lateral or oblique arthrodesis interbody fusion in relation to traditional ones.

\section{MATERIALS AND METHODS}

This systematic review was registered in Prospero under CRD protocol 42018106702.

\section{Search strategy}

The research used the following databases: Medline via PubMed (1966-2018), Lilacs via Virtual Health Library (VHL) (1982-2018), Cochrane Collaboration/Central and Cohrane/Dare Cochrane Controlled Trials Register, without languages or publication date restrictions and with design for prospective cohorts and randomized clinical trials. When more than one study with the same intervention was described by the same author, only the most current was included. Figure 1 describes the search strategy used on Medline via PubMed, the same used for the other databases with the terms adapted to the base.

\begin{abstract}
((/(“Intervertebral disc degeneration” [mh] OR "Disc Degeneration” [mh] OR "Degenerative disc disease" [tw] OR spondylolisthesis [tw] OR Degenerative disease [tw] OR degenerative scoliosis [tw] OR adult degenerative scoliosis [tw] OR adult scoliosis [tw] OR spinal stenosis [tw] OR lumbar spinal stenosis [tw] OR Zygapophyseal Joint [mh] OR Back Pain [mh] OR low back pain [mh] OR low back pain [tw] OR facet joint* [tw] OR lumbar pain [tw] OR Intervertebral disk degeneration [mh] OR Lumbago [tw] OR sciatic neuropathy [mh] OR Spondylolisthesis [mh] OR Spondylolysis [mh] OR spinal stenosis [mh] OR neurogenic claudication [tw] OR Intermittent Claudication [mh] OR Spondylodiscitis [tw] OR hernia* [tw] OR prolapse ${ }^{*}[\mathrm{tw}]$ OR extru* [tw]) AND (transpsoas [tw] OR interbody fusion [tw] OR LLIF [tw] OR XLIF [tw] OR lateral interbody [tw] OR OLIF [tw] OR oblique lumbar interbody fusion [tw] OR fusion [tw] OR extreme lateral interbody fusion [tw] OR oblique lateral fusion [tw] OR DLIF [tw] OR direct lateral interbody fusion [tw] OR posterolateral fusion [tw] OR in situ fusion [tw] OR interbody fusion [tw])) AND (((meta-analysis [pt] OR Systematic Reviews [tw] OR randomized controlled trial [pt] OR controlled clinical trial [pt] OR randomized controlled trials [mh] OR random allocation [mh] OR double-blind method [mh] OR single-blind method [mh] OR clinical trial [pt] OR clinical trials [mh]))))
\end{abstract}

Figure 1. Medline search strategy via Pubmed

\section{Selection criteria and study eligibility}

We selected studies with patients older than 18 years, with degenerative disc disease, without other diseases described. The variables considered were related to measures of disability and low back pain, measured by the Oswestry's disability index (ODI) and the visual analog scale (VAS), respectively, in addition to blood loss greater than $100 \mathrm{~mL}$ and surgical time.

\section{Data extraction}

The data were extracted independently by two authors (AN and $\mathrm{RD}$ ). A third author (DM) was consulted to control differences. The primary outcomes analyzed were: low back pain, using the VAS scale; lumbar disability, through the ODI scale; and consolidation of arthrodesis using imaging. Secondary outcomes were surgical time, blood loss, hospital stay and clinical complications.

\section{Statistical analysis and synthesis of results}

We performed a descriptive analysis of the results to characterize the variables and experiments. The results are presented in tabular form, considering the measures of means, standard deviation and proportion according to the nature of the variable. Heterogeneity was evaluated using the $\mathrm{I}^{2}$ and chi-square method.

Aiming to summarize the results of the study for the variables considered, the meta-analysis methodology was used, combining the results of the experiments so that average and proportion estimates are more reliable to reality. The meta-analysis combines the results of the studies, both for mean and proportion, from weighted average, such that the weights assigned to each study are calculated by means of the inverse variance method, considering the approaches of fixed and random effects, the latter being best suited in case of heterogeneity between the experiments, as it considers a random effect associated with each study, being therefore more comprehensive and preferable.

To perform the analyses, the meta and Metafor packages of the statistical environment $R$ were used and the significance levels set at $5 \%$ in all cases.

\section{Risk of bias}

Bibliographic research articles were critically reviewed by two authors regarding their suitability for inclusion in the study, according to the Cochrane Collaboration critical review list. ${ }^{10}$ All data from this study were extracted from articles, with conclusions drawn based on the data presented. The Cochrane Risk of Bias Tool was used to critically assess the risk of bias. ${ }^{11}$

\section{RESULTS}

Carried out on August 19th of 2008, the search strategies resulted in 1,265 articles found, complemented by active search, totaling 1,319 articles. After applying the selection and eligibility criteria, the review included three articles (Figure 2).

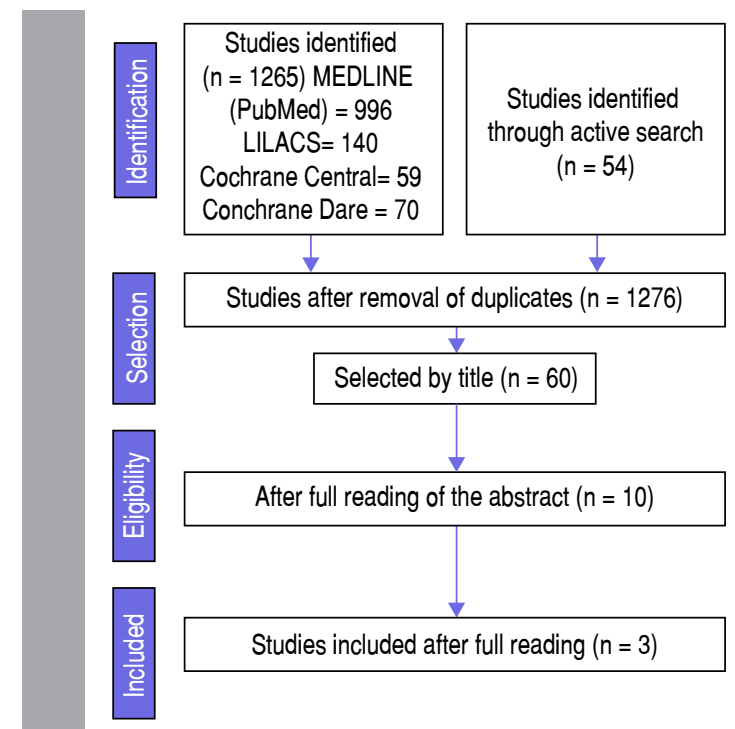

Figure 2. Article selection flowchart.

The studies are represented by numbers, as shown in Table 1, with studies 1 and 2 being prospective cohorts and 3 a randomized clinical trial. In all studies, patients presented different degrees of low back pain, with impaired quality of life and underwent the analyzed methods of interbody fusion. For results analysis, we grouped the studies of similar methodology (cohorts) into meta-analysis ${ }^{12,13}$ and 
evaluated the randomized clinical trial ${ }^{14}$ separately. This evaluated the risk of bias showed in Figure 3.

Table 2 shows the descriptive measures considering the variable related to the VAS pain scale score. First, it is noted that the three studies vary in number of individuals effectively analyzed, with study 1 having approximately twice as many patients as study 3 . It is also seen that the initial means are close between studies, varying between 7.2 and 7.8 , while study 3 presented the biggest difference, with a mean of 5.4. We also observed that the standard deviation of the difference in study 1 is the highest in relation to the others (3.1), while study 3 has no information on this statistic.

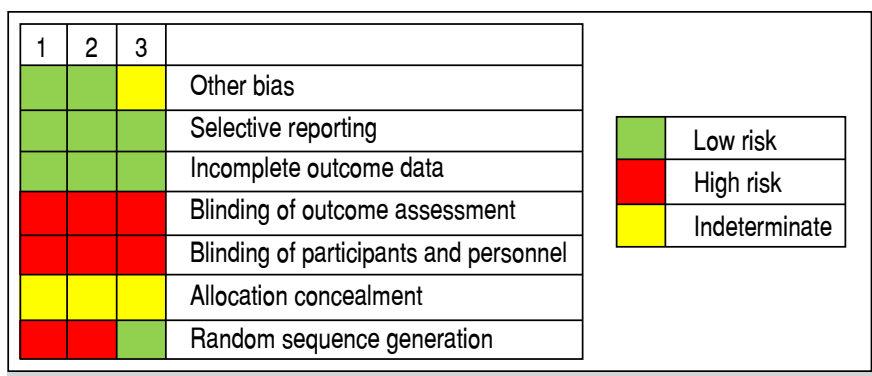

Figure 3. Risk of study bias.

Table 1. Information on the studies considered in the analysis.

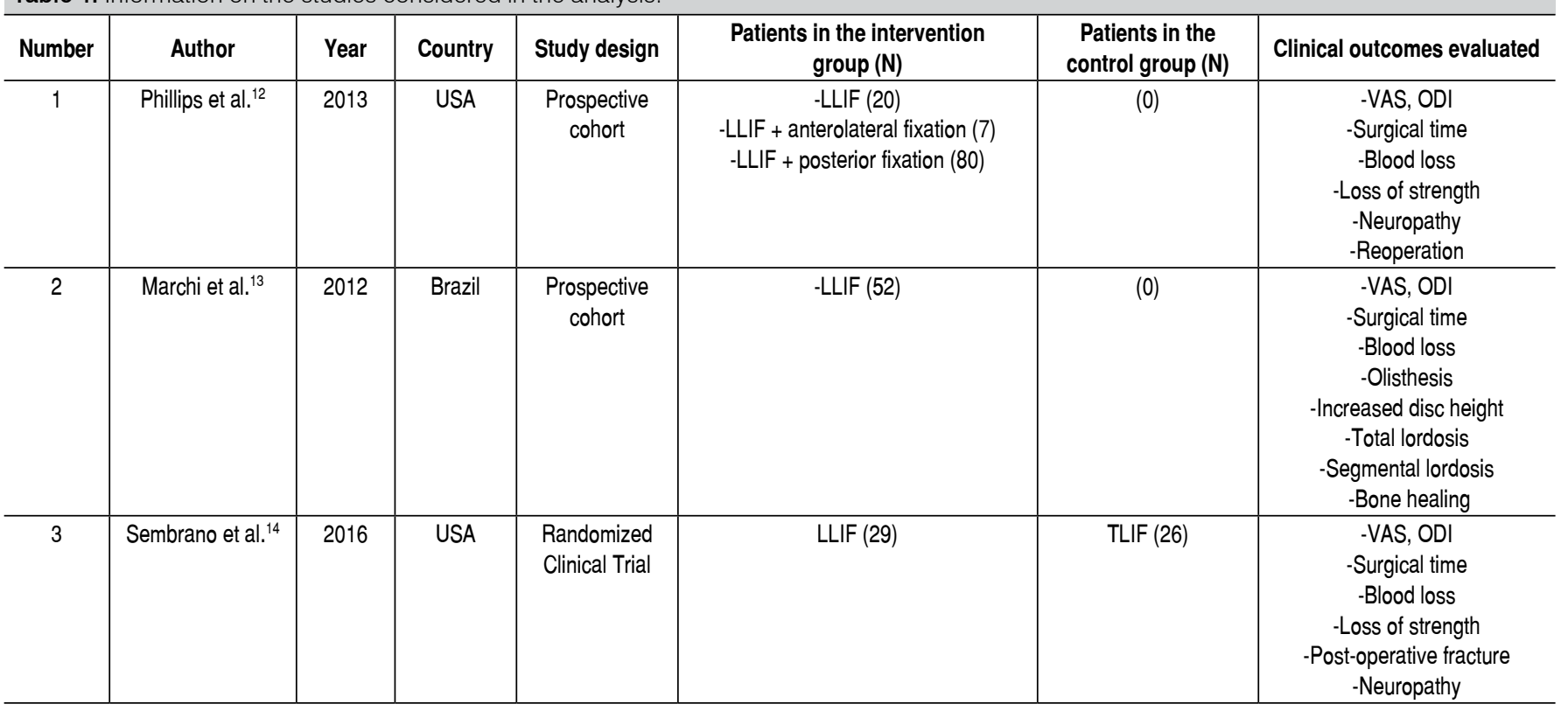

Table 2. Descriptive measures of the VAS scale scores according to the study.

\begin{tabular}{c|c|c|c|c|c}
\hline Study & $\mathbf{N}$ & Initial mean & Final mean & Mean difference & SD \\
\hline 1 & 82 & 7.20 & 3.8 & 3.40 & 3.1 \\
\hline 2 & 52 & 7.80 & 3.1 & 4.70 & 2.18 \\
\hline 3 & 42 & 7.3 & 1.9 & 5.40 & - \\
\hline
\end{tabular}

SD: Standard deviation of the difference.

Table 3 shows the descriptive measures related to the ODI scale score according to each study included in the review. It this respect, study 2 had the highest initial mean measure (66.00), in addition to the highest mean difference (36.00), while the lowest mean difference found was relative to study 1 (21.50). The standard deviations of the differences were close between the studies, however, study 3 provided no information on the difference deviation.

Table 3. Descriptive measures of the ODI scale scores according to the study.

\begin{tabular}{c|c|c|c|c|c}
\hline Study & N & Initial mean & Final mean & Mean difference & SD \\
\hline 1 & 82 & 48.50 & 27.00 & 21.50 & 20.00 \\
\hline 2 & 52 & 66.00 & 30.00 & 36.00 & 16.80 \\
\hline 3 & 42 & 43.00 & 20.00 & 23.00 & - \\
\hline
\end{tabular}

SD: Standard deviation of the difference.
Regarding surgical time, Table 4 shows that studies 1 and 3 presented the highest mean measures (177.90 and 171 minutes, respectively), while study 2 had the lowest mean time (73.20 minutes). There are also differences between the standard deviations of the studies, being the highest relative to study 1 (60.59) and the lowest to study 2 (31.40).

Table 4. Descriptive measures of mean surgical time in minutes according to the study.

\begin{tabular}{c|c|c|c}
\hline Study & N & Mean & SD \\
\hline 1 & 82 & 177.90 & 60.59 \\
\hline 2 & 52 & 73.20 & 31.40 \\
\hline 3 & 42 & 171.00 & - \\
\hline
\end{tabular}

Similarly to previous cases, we see that study 3 provides no information regarding the standard deviation for this variable.

Regarding blood loss, in study 1, the LLIF procedure, $62.5 \%$ of patients had an estimated blood loss of $100 \mathrm{~mL}$ or less, and in only 9 patients (8.4\%) bleeding reached $300 \mathrm{~mL}$. In study 2, the mean blood loss was $<50 \mathrm{~mL}$. In study 3 , blood loss was significantly lower in LLIF than in the TLIF group, with $79 \%$ versus $27 \%$ of cases, respectively, resulting in $<100 \mathrm{~mL}$ of blood loss, $p<0.001$. For the meta-analysis results referring to the VAS and ODI variables, we considered the mean difference (final - initial) as an 
effect measure, evaluated for a group (lateral), whereas for surgical time and blood loss, means and proportions were considered as measures of effect, respectively.

We observed that the fixed and random effects models (Figure 4) were slightly different for this case, with the average difference estimates equal to 4.13 and 4.06 , with $95 \%$ confidence intervals for this measure of $(3.69 ; 4.57)$ and $(2.79 ; 5.33)$, respectively. Thus, the results allow us to conclude that the average difference between moments is statistically significant, i.e., there was a greater reduction of 2 points in the VAS, which is established as clinically significant from the intervention. ${ }^{15}$ In addition, there is evidence of statistically significant heterogeneity $\left(I^{2}=88 \%, p<0.001\right)$.

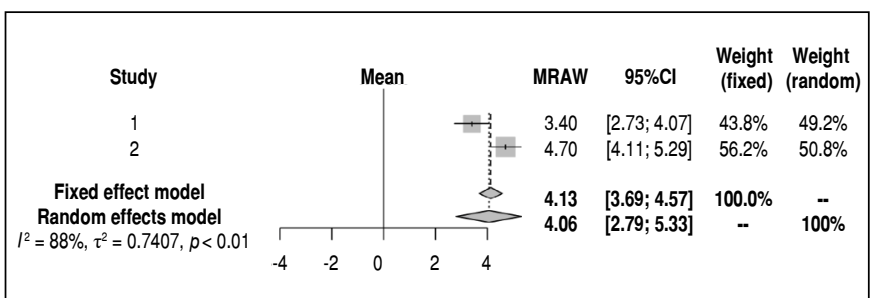

Figure 4. Meta-analysis results for the mean difference (before - after) of the VAS scale scores.

Figure 5 represents the meta-analysis results for the difference in scores on the ODI scale, considering the initial mean measure minus the final of studies 1 and 2, as study 3 presented insufficient information for this type of analysis.

The fixed and random effects models showed different results in this case, with the average difference estimates equal to 28.36 and 28.73 associated with $95 \%$ confidence intervals of (25.22; $31.50)$ and $(14.52 ; 42.94)$ for the fixed and random effect model, respectively. There was a significant reduction in the ODI score from the intervention, which is established as clinically significant from 4.45 points. ${ }^{16}$ Additionally, we found statistical evidence of heterogeneity $\left(I^{2}=95 \%, p<0.001\right)$.

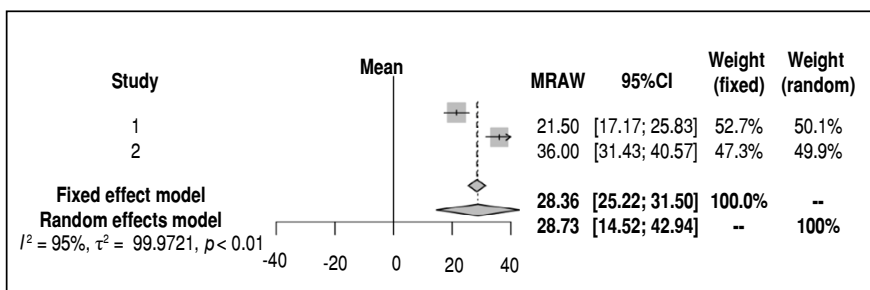

Figure 5. Meta-analysis results for the mean difference (before - after) of the ODI scale scores.

Figure 6 shows meta-analysis results for surgical time, also disregarding study 3 due to lack of information on the variability of this measure. There is a considerable difference in the results according to the approach used. The average time estimated by the fixed effects model is $104.35 \mathrm{~min}(95 \% \mathrm{Cl} 97.20 ; 111.50)$, while by the random effects model, due to the greater balance in weights, is $125.43 \mathrm{~min}$ and the confidence interval is broader (22.82; 228.03). In addition, we found great heterogeneity among the studies, being statistically significant $\left(I^{2}=99 \%, p<0.001\right)$.

Considering the proportion of cases with blood loss greater than $100 \mathrm{~mL}$, we see from the results shown in Figure 7 that there was a difference between the results of the models again, with the random effects model showing milder weightings, which resulted in a lower estimated proportion of $20 \%$ (: $7 \%$; $46 \%$ ), while the fixed effects model attributed greater weight to studies with different proportions other than 0 , leading to the estimated proportion of 31\% and 95\% confidence interval associated equal to (24\%; 40\%). Finally, there is evidence of significant heterogeneity $\left(I^{2}=82 \%, p<0.001\right)$.

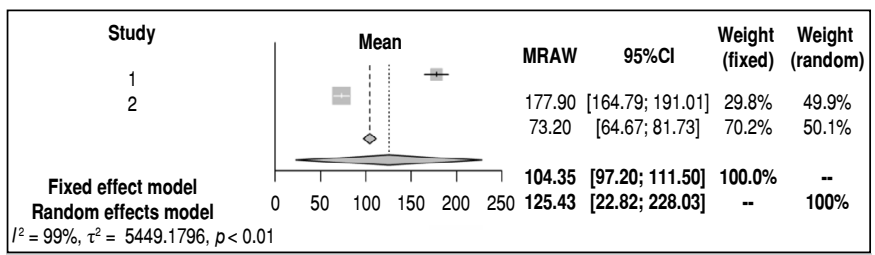

Figure 6. Meta-analysis results for mean surgical time.

\begin{tabular}{|c|c|c|c|c|c|c|c|c|c|}
\hline \multirow{4}{*}{$\begin{array}{c}\text { Study } \\
1 \\
2 \\
3\end{array}$} & Events & Total & Mean & & & \multicolumn{2}{|c|}{ Proportion $95 \% \mathrm{Cl}$} & $\begin{array}{l}\text { Weight } \\
\text { (fixed) }\end{array}$ & $\begin{array}{l}\text { Weight } \\
\text { (random) }\end{array}$ \\
\hline & 31 & 82 & & & & & & & \\
\hline & 0 & & & & & 0.38 & {$[0.27 ; 0.49]$} & $71.8 \%$ & $45.3 \%$ \\
\hline & 9 & 42 & & & & 0.00 & & $1.8 \%$ & $13.7 \%$ \\
\hline \multirow{4}{*}{$\begin{array}{r}\text { Fixed effect mo } \\
\text { Random effects } \\
L^{2}=82 \%, \tau^{2}=0.7974\end{array}$} & & & & & & 0.21 & {$[0.10 ; 0.37]$} & $26.3 \%$ & $41.0 \%$ \\
\hline & & 176 & & & & & & & \\
\hline & & & $T$ & 1 & & 0.31 & {$[0.24 ; 0.40]$} & $100.0 \%$ & - \\
\hline & $p<0.01$ & & 0.10 .2 & 0.3 & 0.4 & 0.20 & {$[0.07 ; 0.46]$} & -- & $100 \%$ \\
\hline
\end{tabular}

Figure 7. Meta-analysis results for the proportion of cases with blood loss greater than $100 \mathrm{~mL}$.

As for the evaluation of arthrodesis consolidation, it was infeasible to perform meta-analysis of these data due to the difference in follow-up time for each study and the conditions selected for the outcome, thus we performed an independent analysis. Study 1 showed that $58 \%$ of the patients who underwent the procedure presented complete fusion after 12 months of follow-up, 39\% partial and $3 \%$ observed no consolidation. In study 2 , we observed that $86.5 \%$ of the patients presented total consolidation. All patients in study 3 showed, by magnetic resonance imaging, complete fusion at 12 months for the LLIF approach and $74 \%$ for TLIF, being selected for this analysis only patients with low range of motion impairment. We assessed the length of hospital stay for surgical approaches in articles 1 and 3, with the first being 3.8 days on average and the last 2 days.

Regarding clinical complications, we observed in study 1 that $34 \%$ of patients had some degree of postoperative muscle weakness, of which $81 \%$ showed weakness in hip flexion, and five patients presented weakness after 25 months. During the 24-month follow-up, 13 patients needed a new surgical approach. In study 2, 10 patients presented weakness in the psoas and five patients had numbness in the anterior region of the thigh, with both conditions resolving within 6 weeks in all cases.

Study 3 observed postoperative hip flexion weakness in $31 \%$ of patients with LLIF, all of which resolved within six month of the postoperative period. The study also recorded a femoral neuropathy, with distal weakness of $4 / 5$, in the LLIF group, with complete resolution within six months. We found no loss of postoperative hip strength or distal weakness in the TLIF cohort.

\section{DISCUSSION}

In this study, we assessed two prospective cohort studies and a randomized clinical trial evaluating lateral interbody fusion, totaling 188 patients. The results show that in relation to the primary outcomes (Oswestry's disability index and low back pain by VAS) the LLIF approach presents improvement in both parameters when compared with the moment prior the intervention; showing a difference in VAS of 4.13 for the fixed analysis and 4.06 for the randomized analysis; ODI showed a difference of 28.36 and 28.73 , respectively. 
For better data analysis, we compared the results with the TLIF approach presented in study number 3 . This shows an average improvement of 3.6 in VAS, thus being lower than LLIF $(3.92 ; 3.85)$, which shows greater efficiency of the second method. For the ODI scale, TLIF presents a difference of 25 points, being similar to LLIF (25.91; 24.32) and thus being unable to establish which method is the most efficient; blood loss greater than $100 \mathrm{~mL}$, in the TLIF group, occurred in $73 \%$ of the procedures, this value being very low when compared with LLIF (30\%).

Regarding the time of arthrodesis consolidation, it was impossible to establish which method has the best result, due to the difference in analysis between the studies, but when performing individual analysis of study 3 , we verify a $28 \%$ difference in patients who obtained complete fusion in 12 months. It should also be noted that the method used to assess arthrodesis in this study was magnetic resonance, knowing that this method is less than ideal for assessing bone healing.

The length of hospital stay, evidenced in only 2 studies, one of which was the randomized clinical trial, shows similarity between the approaches (LLIF and TLIF), where both had two days of hospitalization. The short surgical time and bleeding presented in study 2 are noteworthy - these data raise the hypothesis of the difference in the learning curve between services, in relation to the applied technique.

The main limitation of the present study is not to have found randomized clinical trials that could be compared among themselves in the literature, performing analysis among the best quality studies available. As another limitation, we noticed that study 1 evaluated three different types of intervention, which were analyzed collectively in this review, reducing the number of participants from 107 to 82 for the 24-month follow-up. In addition, in study 2, we did not identify the number of patients who underwent the LLIF and TLIF procedures with a 24-month follow-up separately, thus considering the total value. As an attempt at a solution, we made communication through an e-mail address, but obtained no response in time.

Regarding the costs of the procedures, the absence of cost data in the three selected studies prevented assessing this variable to know which one is more advantageous. Although techniques with anterolateral approach are considered less invasive, the studies showed a high rate of complications, which were transient, generally associated with the multi-level approach in more complex cases, with removal of the psoas muscle, showing muscle damage or neuropraxia of neural roots of the lumbar plexus and pseudarthrosis.

\section{CONCLUSION}

In view of what was discussed by the analyzed studies, the LLIF surgical approach presents an improvement in relation to TLIF, but the authors considered the number of studies, with only one randomized clinical trial, insufficient to establish the most efficient surgical methodology. Thus, greater availability of studies discussing the themes described in this review is needed.

\section{ACKNOWLEDGMENTS}

The study received funding from the Sociedade Brasileira de Coluna.

AUTHORS' CONTRIBUTIONS: Each author contributed individually and significantly to the development of this article. AAN: writing of the article, review and preparation of the entire research project; RGD: data analysis, writing of the article and preparation of the entire research project; MW: review of the article and preparation of the entire research project; DM: writing of the article, statistical analysis and review of the article.

\section{REFERENCES}

1. Kim SM, Lee SH, Lee BR, Hwang JW. Analysis of the correlation among age, disc morphology, positive discography and prognosis in patients with chronic low back pain. Ann Rehabil Med. 2015;39(3):340-6.

2. 2. Haefeli M, Kalberer F, Saegesser D, Nerlich AG, Boos N, Paesold G. The course of macroscopic degeneration in the human lumbar intervertebral disc. Spine. 2006;31(14):1522-31.

3. Silva MR, Domingues CJ, Pinto RP, Neves N, Matos RM, Tulha JM, et al. New perspectives on degenerative disease treatment. Acta Reumatol Port. 2009;34(2B):327-35.

4. Noshchenko A, Hoffecker L, Lindley EM, Burger EL, Cain CM, Patel VV. Long-term treatment effects of lumbar arthrodeses in degenerative disk disease. J Spinal Disord Tech. 2015;28(9):E493-521.

5. Kalichman L, Kim DH, Li L, Guermazi A, Berkin V, Hunter DJ. Spondylolysis and spondylolisthesis: prevalence and association with low back pain in the adult community-based population. Spine. 2009;34(2):199-205.

6. Costa F, Sassi M, Ortolina A, Cardia A, Assietti R, Zerbi A, et al. Stand-alone cage for posterior lumbar interbody fusion in the treatment of high-degree degenerative disc disease: design of a new device for an "old" technique. A prospective study on a series of 116 patients. Eur Spine J. 2011;20(S1):46-56.

7. Cloward RB. The treatment of ruptured lumbar intervertebral discs by vertebral body fusion. J Neurosurg. 1953;10(2):154-68.

8. Patel VC, Park DK, Herkowitz HN. Lateral transpsoas fusion: indications and outcomes. Sci World J. 2012;2012:893608.

9. Xu DS, Walker CT, Godzik J, Turner JD, Smith W, Uribe JS. Minimally invasive anterior, lateral, and oblique lumbar interbody fusion: a literature review. Ann Transl Med. 2018;6(6):104.
10. Higgins JP, Thompson SG. Quantifying heterogeneity in a meta-analysis. Stat Med. 2002;21(11):1539-58.

11. Higgins JPT, Altman DG, Sterne JAC. Chapter 8: Assessing risk of bias in included studies. In: Higgins JPT, Churchill R, Chandler J, Cumpston MS editors. Cochrane Handbook for Systematic Reviews of Interventions version 5.2 .0 [Internet]. Cochrane; 2017 [updated 2017 June; accessed on 2020 Aug 20]. [about 73 p]. Available from: https://handbook-5-1.cochrane.org/ chapter_8/8_assessing_risk_of_bias_in_included_studies.htm

12. Phillips FM, Isaacs RE, Rodgers WB, Khajavi K, Tohmeh AG, Deviren V, et al. Adult degenerative scoliosis treated with XLIF: clinical and radiographical results of a prospective multicenter study with 24-month follow-up. Spine. 2013;38(21):1853-61.

13. Marchi L, Abdala N, Oliveira L, Amaral R, Coutinho E, Pimenta L. Stand-alone lateral interbody fusion for the treatment of low-grade degenerative spondylolisthesis. Sci World J. 2012;2012:456346.

14. Sembrano JN, Tohmeh A, Isaacs R, SOLAS Degenerative Study Group. Two-year comparative outcomes of MIS lateral and MIS transforaminal interbody fusion in the treatment of degenerative spondylolisthesis: Part I: clinical findings. Spine. 2016;41(Suppl 8):S123-32.

15. Coelho RA, Siqueira FB, Ferreira PH, Ferreira ML. Responsiveness of the Brazilian-Portuguese version of the oswestry disability index in subjects with low back pain. Eur Spine J. 2008;17(8):1101-6.

16. Carvalho DS, Kowacs PA. Avaliação da intensidade da dor. Migrâneas Cefaleias. 2006;9(4):164-8. 